\title{
Isolamento ao ruído de impacto de laje pré- fabricada nervurada com vigotas protendidas e lajotas cerâmicas
}

\author{
Impact noise isolation of prefabricated ribbed slab with \\ prestressed joist and ceramic block
}

\begin{abstract}
Alessandra Haas
Willian Magalhães de Lourenço

Joaquim Cesar Pizzutti dos Santos

Jorge Luiz Pizzutti dos Santos

\section{Resumo}

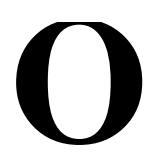

ruído de impacto é um dos principais fatores de desconforto entre os usuários de edificações de múltiplos pavimentos. Assim, a realização desta pesquisa busca: determinar as propriedades acústicas de isolamento ao ruído de impacto no sistema de laje pré-fabricada nervurada composta de vigotas protendidas e lajotas cerâmicas, em três composições de montagem; avaliar o desempenho para ruído de impacto da técnica em piso flutuante sobre a laje, com uso de quinze materiais resilientes diferentes; comparar os resultados obtidos para as diversas composições de montagem com os critérios da norma de desempenho 15575-3:2013. Os ensaios foram realizados no laboratório da UFSM, em conformidade com parâmetros da ISO 16283-2:2020 e ISO 717-2:2020, para determinar o nível de pressão sonora de impacto padrão ponderado $\left(L_{n T, w}^{\prime}\right)$ de cada composição ensaiada. Pode-se concluir que a tipologia construtiva, com contrapiso de $4 \mathrm{~cm}$ e revestimento cerâmico, necessita de tratamento acústico para se enquadrar na normativa brasileira, e que a utilização da técnica em piso flutuante se apresenta como uma boa solução, visto que a grande maioria das composições com materiais resilientes alcança nível intermediário da norma entre $56 \mathrm{~dB}$ e $65 \mathrm{~dB}$.
\end{abstract}

${ }^{1}$ Alessandra Haas ${ }^{1}$ Universidade Federal de Santa Maria Santa Maria - RS - Brasil

${ }^{2}$ Willian Magalhães de Lourenço ${ }^{2}$ Universidade Federal de Santa Maria Santa Maria - RS - Brasil

${ }^{3}$ Joaquim Cesar Pizzutti dos

Santos

${ }^{3}$ Universidade Federal de Santa Maria Santa Maria - RS - Brasil

${ }^{4}$ Jorge Luiz Pizzutti dos Santos ${ }^{4}$ Universidade Federal de Santa Maria Santa Maria - RS - Brasil

Recebido em 16/06/20 Aceito em 09/08/21
Palavras-chave: Conforto acústico. Isolamento acústico. Ruído de impacto.

\section{Abstract}

Impact noise is one of the main discomfort factors among users of multi-storey buildings. Thus, this research seeks to: determine the acoustic properties of insulation against impact noise in the prefabricated ribbed slab system, composed of prestressed joists and ceramic blocks in three montage compositions, evaluate the performance of insulation against impact noise of the technique on floating floor over the slab, using fifteen different resilient materials, and compare the results obtained for the various compositions with the Brazilian criteria of performance standard 15575-3:2013. The tests were carried out in the UFSM laboratory, in accordance with ISO 140-7 parameters updated to ISO 16283-2:2020, and ISO 717-2:2020, to determine the weighted standard impact sound pressure level $\left(L_{n T, w}^{\prime}\right)$ of each composition tested. It can be concluded that the constructive typology, with a 4 $\mathrm{cm}$ subfloor and ceramic coating, needs acoustic treatment to fit the Brazilian regulations, and that the use of the floating floor technique is a good solution, since the great majority compositions with resilient materials reach an intermediate level of the standard between 56 and $65 \mathrm{~dB}$.

Keywords: Acoustic confort. Acoustic isolation. Impact noise.

HAAS, A.; LOURENÇO, W. M. de; SANTOS, J. C. P. dos; SANTOS, J. L. P. dos. Isolamento ao ruído de impacto de laje pré-fabricada nervurada com vigotas protendidas e lajotas cerâmicas. Ambiente Construído, Porto Alegre, v. 22, n. 1, p. 105-123, jan./mar. 2022. 


\section{Introdução}

Em questão de décadas o mercado da construção civil experimentou um exponencial crescimento frente ao desenvolvimento das cidades (urbanização) e à busca por moradia (verticalização). A busca por maximização dos lucros na produção de edificações habitacionais levou a cadeia produtiva a racionalizar e a reduzir os custos das construções, traduzindo-se em redução de espessuras de paredes e pisos e remoção de algumas soluções construtivas, resultando ao final em perda de desempenho nas novas edificações (PIERRARD; AKKERMAN, 2013).

Consequentemente, o desenvolvimento de novas tecnologias buscou aprimorar ainda mais as questões de redução de custos, consumo de materiais e mão de obra. O crescimento desordenado, associado ao surgimento de novas tecnologias, e questões culturais colaboraram para o aumento de problemas relacionados ao conforto acústico (CARVALHO, 2010), o qual muitas vezes é considerado subjetivo, uma vez que o desempenho acústico de uma edificação é praticamente invisível, estando dentro do sistema construtivo e diretamente relacionado à técnica e materiais empregados na edificação, passando despercebido aos olhos e ao conhecimento da população em geral, de modo que o problema só será percebido após uso e ocupação do local (DUARTE; VIVEIROS, 2010).

Nesse contexto, a Associação Brasileira de Normas Técnicas (ABNT) traz a NBR 15575 (ABNT, 2013) Edificações Habitacionais - Desempenho, que visa à qualidade das construções brasileiras, definindo desempenhos mínimos a serem atingidos por vários quesitos da construção de habitações, dentre eles os parâmetros acústicos, que regulam os níveis de desempenho de paredes, esquadrias e pisos.

Sobre a norma em questão Pierrard e Akkerman (2013) destacam o seguinte:

Conforme definido nas incumbências dos intervenientes previstos na NBR 15575, cabe aos fabricantes de sistemas construtivos [...] apresentar ao projetista e ao empreendedor o desempenho de seus sistemas quando medidos em laboratório. E cabe ao empreendedor analisar estes dados, quanto à capacidade de atenderem a condição de desempenho em campo exigida do incorporador/construtor. [...] o incorporador/construtor deve saber, de antemão, as condições de execução e instalação necessárias para atender aos requisitos e critérios estabelecidos.

Portanto, para que o sistema construtivo atenda aos padrões de desempenho exigidos pela norma, é necessário o estudo de desempenho dos materiais que o compõem. Logo, muitas empresas e profissionais buscam conhecimento e embasamento para compreender e respeitar as exigências da norma em seus projetos.

Destarte, faz-se preponderante a realização de pesquisas acerca do comportamento das diferentes tecnologias construtivas utilizadas, em âmbito nacional, visto que os sistemas construtivos de outros países são distintos dos utilizados no Brasil, o que dificulta o aproveitamento de dados de pesquisas advindas do exterior (CORNACCHIA; ROSSI; VIVEIROS, 2009).

Logo, a realização desse estudo faz-se relevante para o mercado da construção civil brasileira, pois possibilita determinar as propriedades acústicas de uma das tecnologias construtivas populares no mercado atualmente, corroborando para bancos de dados de pesquisas, no viés de desempenho acústico de sistemas de pisos, aliados à técnica de pisos flutuantes.

Por fim, os dados obtidos com a realização da pesquisa poderão servir de respaldo para futuras recomendações, intervenções projetuais, buscando melhorar a qualidade das construções e de vida dos usuários.

\section{Referencial teórico}

Conforme a NBR 16313 (ABNT, 2014), isolamento acústico trata da redução da transmissão sonora entre ambientes distintos. Bistafa (2011, p. 315) evidencia que o "[...] controle do ruído envolve a fonte sonora, a trajetória de transmissão e o receptor [...]", e salienta que o "[...] método mais eficaz de isolamento é controlar o ruído na fonte, ou seja, eliminar ou minimizar o ruído na sua origem [...]".

Segundo Carvalho (2010, p. 114-115), "[...] a melhor forma de se absorver qualquer impacto em lajes de pisos, é a adoção de materiais macios em seus acabamentos (tapetes, pisos emborrachados, etc.) [...]". Nunes e Patrício (2016) corroboram que a escolha do revestimento "rígido ou elástico" influencia nos resultados, visto que há uma redução na resposta vibracional nas médias e altas frequências, a partir dos $500 \mathrm{~Hz} c 0 m$ uso de revestimento elástico.

106 Haas, A.; Lourenço, W. M. de; Santos, J. C. P. dos; Santos, J. L. P. dos 
Devido aos benefícios da escolha do revestimento, Carvalho (2010, p. 114-115) contribui que não se pode privar o usuário de adotar pisos cerâmicos, pedras, entre outros. Desse modo, aponta como solução para redução na transferência de impactos os pisos flutuantes, que, sobre bases elásticas, desconecta inteiramente o contrapiso e piso de quaisquer elementos estruturais e/ou de vedações.

Zuchetto, Nunes e Patrício (2016) destacam que "[...] o comportamento dos materiais que compõem os pisos flutuantes pode definir sua eficiência no isolamento ao ruído de impacto [...]", visto que os materiais sofrem alterações decorrentes do carregamento ao longo dos anos.

Outro fator importante destacado por Pedroso (2007) é a existência de pontes acústicas, que ocorrem quando um material rígido acaba unindo, em partes, os elementos estruturais separados pelo material resiliente. Desse modo, as vibrações encontram um caminho para sua propagação, praticamente eliminando a eficácia do material resiliente, ou seja, deve-se ter muito cuidado e atenção ao se executar um piso flutuante, garantindo que não haja contato entre as partes rígidas da estrutura.

Mesmo ao desconectar o piso da estrutura para evitar a transmissão direta, considerada como única forma de transmissão entre recintos por diversos métodos avaliativos, Bistafa (2011, p. 312) destaca que "[...] em situações reais existem as chamadas transmissões secundárias [...]" ou transmissões marginais, que podem interferir diretamente nas avaliações.

$\mathrm{Na}$ mesma linha de pensamento Semprini e Barbaresi (2013) evidenciam que sistemas de piso flutuante testados em laboratório podem atingir desempenhos elevados, porém o desempenho in situ é influenciado pela transmissão secundária, que depende do tipo de junção, da massa e da dimensão das paredes e vigas envolvidas na transmissão.

\section{Normatização}

A norma brasileira que define os requisitos de desempenho das edificações habitacionais é a NBR 15575 (ABNT, 2013). Na parte 3 da respectiva norma, encontram-se os critérios para desempenho do isolamento acústico do sistema de pisos entre unidades autônomas. Os procedimentos para obtenção do parâmetro de avaliação imposto pela norma são descritos nas ISO 16283-2 (INTERNATIONAL..., 2020a) e ISO 717-2 (INTERNATIONAL..., 2020).

A NBR 15575 (ABNT, 2013) foi publicada com intuito de melhorar a qualidade da habitabilidade das edificações, propondo níveis mínimos de desempenho a serem considerados nas mais diversas categorias. $\mathrm{Na}$ referida pesquisa, serão observadas as exigências que constam na parte 3 (requisitos para os sistemas de piso), no que tange ao desempenho acústico, considerando o isolamento de ruído de impacto.

Desse modo, para determinar o isolamento ao ruído de impacto no sistema de pisos, devem-se adotar os parâmetros de verificação especificados pela NBR 15575-3 (ABNT, 2013), listados no Quadro 1, na qual temos como parâmetro de avaliação a normativa internacional ISO 140-7 (INTERNATIONAL..., 1998), que considera medição de isolamento sonoro em campo, ou seja, a normativa considera além da transmissão direta as transmissões secundarias ou por flancos. A ISO 140-7 (INTERNATIONAL..., 1998) foi cancelada em 2015, e substituída pela ISO 16283-2 (INTERNATIONAL..., 2020a), adotada nesta pesquisa, visto que, mesmo em ambiente laboratorial, a pesquisa simula condições de uso e operação de situação em campo. E para a determinação dos valores de nível de pressão sonora padrão ponderado, $L_{n T, w}^{\prime}$ aplica-se a ISO 717-2 (INTERNATIONAL..., 2020).

A NBR 15575-3 (ABNT, 2013) estabelece requisitos mínimos de desempenho obrigatórios, e considera a possibilidade de melhoria na qualidade da edificação, estabelecendo níveis de desempenho intermediário (I) e superior (S) além do mínimo (M), conforme Tabela 1.

\section{Método}

\section{Local e equipamentos}

Os ensaios foram realizados no laboratório da Universidade Federal de Santa Maria (UFSM), constituído pela câmara de recepção, com área de $14,33 \mathrm{~m}$ e volume de $56,32 \mathrm{~m}$ e pelo espaço adjacente superior, aberto, denominado de emissão com área de 14,33 m .

As paredes da câmara de recepção são compostas por blocos de concreto com $19 \mathrm{~cm}$ de espessura, com argamassa de preenchimento entre blocos, e os furos dos blocos foram preenchidos com argamassa traço 1:4 
(areia e cimento, respectivamente). A parede possui reboco de $3 \mathrm{~cm}$ em ambos os lados, totalizando $25 \mathrm{~cm}$ de espessura final.

A laje teste possui vínculo rígido com a estrutura, ou seja, está conectada diretamente nas paredes da câmara de recepção, e também possui eletrodutos em sua composição. Sendo assim, simulam-se condições em campo, determinantes para as normativas utilizadas para a elaboração desta pesquisa. A Figura 1 ilustra planta baixa e corte da câmara de recepção.

Os equipamentos disponibilizados pelo laboratório da Universidade Federal de Santa Maria (UFSM) para os ensaios estão listados no Quadro 2.

\section{Quadro 1 - Parâmetros acústicos de avaliação}

\begin{tabular}{|c|l|c|c|}
\hline Símbolo & \multicolumn{1}{|c|}{ Descrição } & Norma & Aplicação \\
\hline$L_{n T, w}^{\prime}$ & $\begin{array}{l}\text { Nível de pressão sonora de } \\
\text { impacto padrão ponderado }\end{array}$ & $\begin{array}{l}\text { ISO 140-7 } \\
\text { ISO 717-2 }\end{array}$ & Sistema de piso \\
\hline
\end{tabular}

Fonte: NBR 15575-3, tabela 5, p. 20 (ABNT, 2013).

Tabela 1 - Critério e nível de pressão sonora de impacto-padrão ponderado, L'nT,w

\begin{tabular}{l|c|c}
\multicolumn{1}{c|}{ Elemento } & $\boldsymbol{L}^{\prime}{ }_{\boldsymbol{n} \text { T,w }} \mathbf{d B}$ & Nível de desempenho \\
\hline Sistema de pisos separando unidades habitacionais autônomas & 66 a 80 & $\mathrm{M}$ \\
posicionadas em pavimentos distintos & 56 a 65 & $\mathrm{I}$ \\
& $\leq 55$ & $\mathrm{~S}$ \\
\hline $\begin{array}{l}\text { Sistema de piso de áreas de uso coletivo (atividades de lazer e } \\
\text { esportivas, como home theater, salas de ginástica, salão de }\end{array}$ & 51 a 55 & $\mathrm{M}$ \\
festas, salão de jogos, banheiros e vestuários coletivos, & 46 a 50 & $\mathrm{I}$ \\
cozinhas e lavanderias coletivas) sobre unidades habitacionais & $\leq 45$ & $\mathrm{~S}$ \\
autônomas & & \\
\hline
\end{tabular}

Fonte: NBR 15575-3, anexo E, tabela E. 1, p. 40 (ABNT, 2013).

Figura 1 - Planta baixa e corte longitudinal da câmara de recepção

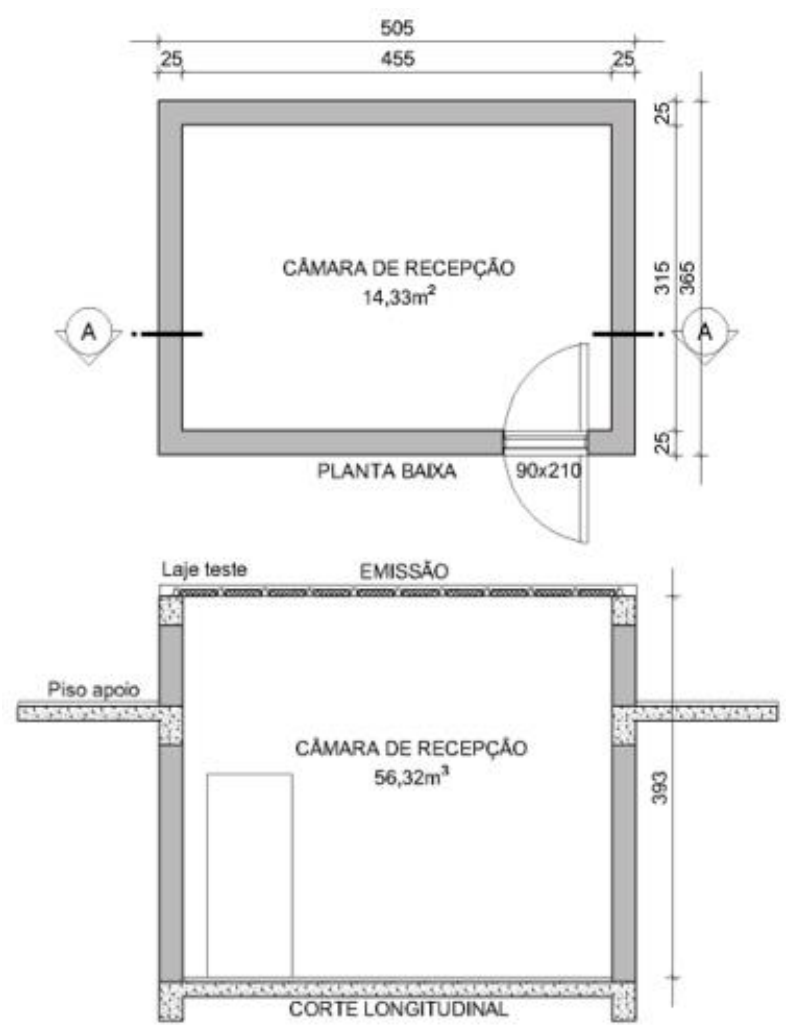

108 Haas, A.; Lourenço, W. M. de; Santos, J. C. P. dos; Santos, J. L. P. dos 


\section{Montagem}

A montagem da laje pré-moldada com vigotas protendidas utilizadas nos ensaios possui as seguintes características: vigota com largura de $10 \mathrm{~cm}$, altura de $8,5 \mathrm{~cm}$ e combinação de 4 fios protendidos de $5 \mathrm{~mm}$; tavelas cerâmicas com largura de $37 \mathrm{~cm}$, altura de $8 \mathrm{~cm}$ e profundidade de $20 \mathrm{~cm}$, e distância intereixos de $47 \mathrm{~cm}$. O esquema de montagem e dimensões podem ser vistos na Figura 2.

Considera-se $5 \mathrm{~cm}$ de mesa de compressão, com concreto usinado de $25 \mathrm{MPa}$, com adição de malha de aço $15 \mathrm{~cm}$ x $15 \mathrm{~cm}$, diâmetro de 4,2 mm. Também foram adicionados eletrodutos 3/4 no seu interior buscando aproximar a amostra da realidade de medições em campo, totalizando a altura final em 13,5 cm, conforme pode ser visualizado na Figura 3.

A laje montada no local de ensaios conforme a descrição pode ser vista na Figura 4.

Além do teste com laje em "osso", para melhor compreensão do comportamento acústico da tipologia construtiva, foram propostas diversas amostras a serem ensaiadas, que são elencadas no Quadro 3.

Os testes com materiais resilientes, no modelo de piso flutuante, foram possíveis devido à utilização de oito placas de contrapiso reduzidas, com dimensões de $1 \mathrm{~m} \mathrm{x} 1 \mathrm{~m}$. As placas foram confeccionadas com argamassa traço 1:4 (cimento e areia, respectivamente), com malha de arame para dar sustentação, alças laterais para facilitar o deslocamento, com espessura final de $4 \mathrm{~cm}$. Na Figura 5(a) tem-se o modelo de placa de contrapiso confeccionada, utilizada nos ensaios da amostra 2.

\section{Quadro 2 - Descrição dos aparelhos disponibilizados para os ensaios}

\begin{tabular}{|l|l|l|}
\hline \multicolumn{1}{|c|}{ Descrição } & \multicolumn{1}{c|}{ Fabricante } & \multicolumn{1}{c|}{ Modelo } \\
\hline Máquina de impacto-padrão & $01 \mathrm{~dB}-$ Metravib & CalpestONE \\
\hline Fonte acústica dodecaédrica & $01 \mathrm{~dB}$ & OMNI 12 \\
\hline Amplificador & $01 \mathrm{~dB}$ & AMPLI 12 \\
\hline Calibrador de nível sonoro & $01 \mathrm{~dB}$ & CAL 21 \\
\hline Medidor de nível de pressão sonora & $01 \mathrm{~dB}-$ Metravib & Black Solo 01 \\
\hline Microfone capacitivo & $01 \mathrm{~dB}-$ Metravib & MCE 212 \\
\hline Pré-amplificador de microfone 01dB & $01 \mathrm{~dB}-$ Metravib & PRE 21 S \\
\hline Termo-higro-barômetro digital & Instrutherm & THB-100 \\
\hline Software 01dB & dBBati Building acoustics & versão 5.3 \\
\hline
\end{tabular}

Figura 2 - Dimensões de vigota e tavela cerâmica para montagem da laje protendida

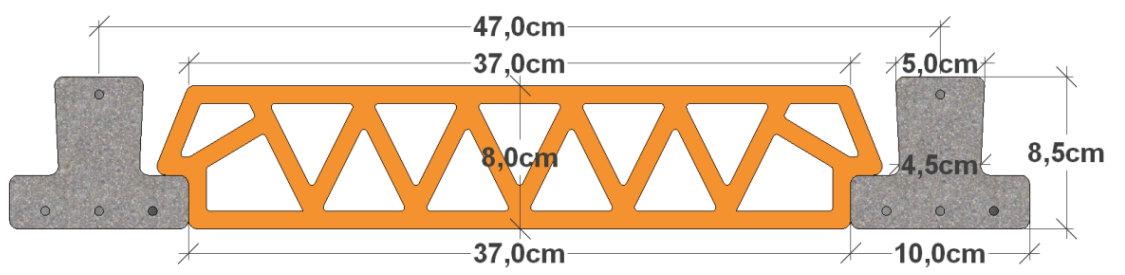

Figura 3 - Dimensões finais da laje com mesa de compressão e contrapiso de regularização

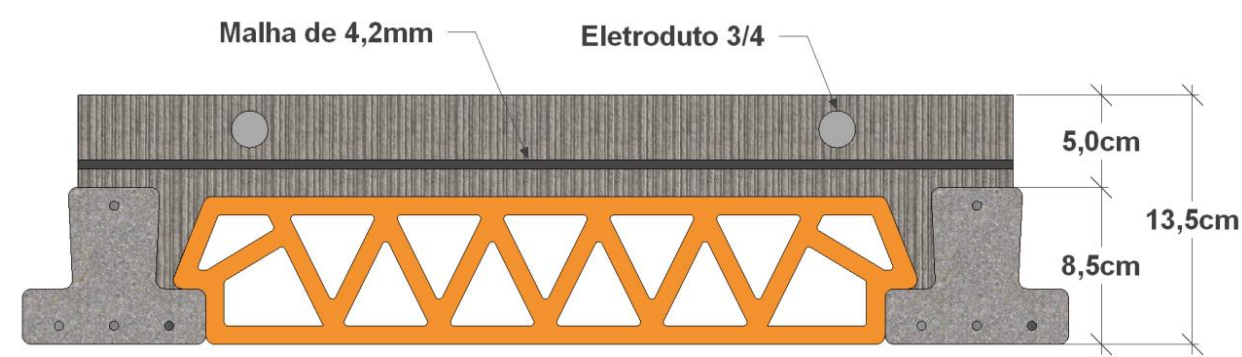


Figura 4 - Montagem da composição no local de ensaio

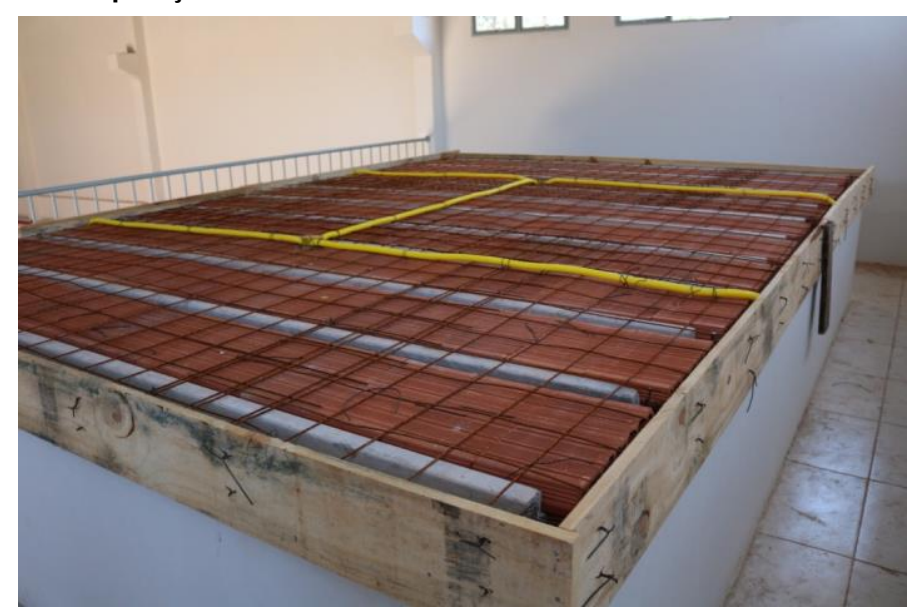

Quadro 3 - Amostras para ensaio

\begin{tabular}{|c|c|c|}
\hline Amostra & Composição & Montagem \\
\hline 1 & Laje em "osso" & LAJE EM OSSO $\rightarrow$ \\
\hline 2 & Laje + contrapiso $(4 \mathrm{~cm})$ & 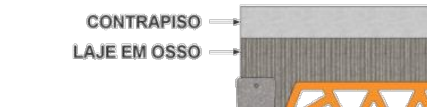 \\
\hline 3 & $\begin{array}{l}\text { Laje }+ \text { contrapiso }(4 \mathrm{~cm})+ \\
\text { revestimento cerâmico }\end{array}$ & $\begin{array}{l}\text { REVESTIMENTO } \rightarrow- \\
\text { CONTRAPISO } \rightarrow \\
\text { LAJE EM OSSO } \rightarrow\end{array}$ \\
\hline 4 a 18 & $\begin{array}{l}\text { Laje }+ \text { material resiliente }+ \\
\text { contrapiso }(4 \mathrm{~cm})+ \\
\text { revestimento cerâmico }\end{array}$ & $\begin{array}{r}\text { REVESTIMENTO } \\
\text { CONTRAPISO } \\
\text { MATERRAL RELIIINETE } \\
\text { LAJE EM OSSO }\end{array}$ \\
\hline
\end{tabular}

Quatro dessas placas receberam revestimento cerâmico, totalizando $5 \mathrm{~cm}$ de espessura final.

A Figura 5(b) apresenta o modelo de placa com revestimento cerâmico, utilizada nos ensaios das amostras 3 a 18.

A superfície da laje onde foram posicionadas as placas de contrapiso recebeu uma fina camada de nivelamento, de modo a proporcionar maior compatibilidade entre os elementos. Após o posicionamento das 4 placas de contrapiso sobre a laje, elas permaneciam no local até o final dos ensaios, sendo movimentada somente a máquina de impacto.

\section{Materiais resilientes e revestimento}

Como material de revestimento da placa do contrapiso, utilizou-se o piso cerâmico de porcelanato $50 \mathrm{~cm} \mathrm{x}$ $50 \mathrm{~cm}$, com $9 \mathrm{~mm}$ de espessura.

Os materiais resilientes utilizados na composição do sistema de piso flutuante das amostras 4 a 18 estão elencados abaixo.

Lã de vidro: material fibroso, fabricado a partir de sílica e sódio, revestido com película impermeável e vendida em placas ou rolos. Na Figura 6 pode ser visto o painel de $15 \mathrm{~mm}$, ensaiado sob contrapiso. 
Figura 5 - Placa de contrapiso (a) e placa com revestimento cerâmico (b), utilizadas nos ensaios

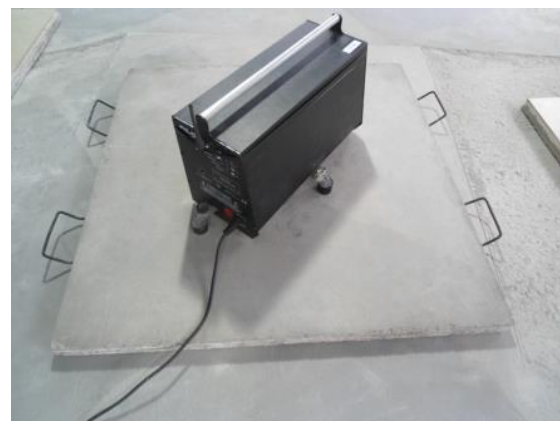

(a)

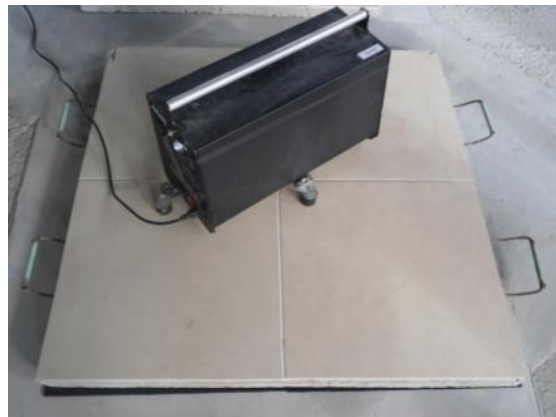

(b)

Figura 6 - Painel de lã de vidro $15 \mathrm{~mm}$ sob contrapiso

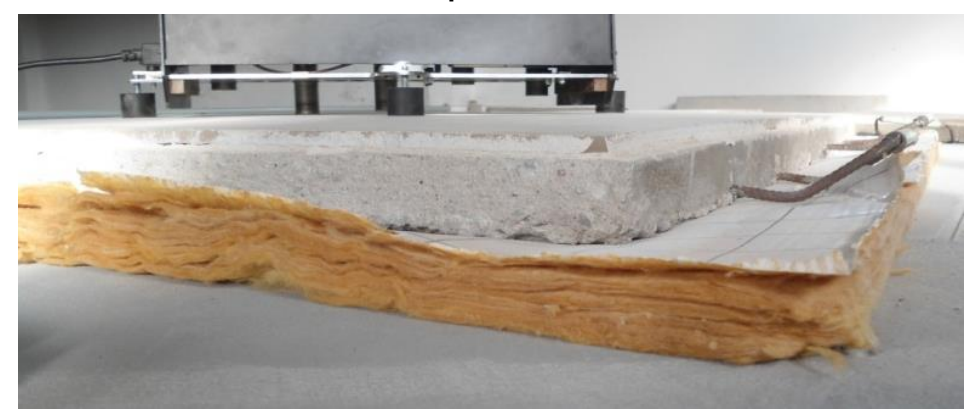

Lã de poliéster (PET): material fibroso, feito por meio da reciclagem de garrafas PET, revestido com película impermeável, vendido em rolos. As mantas ensaiadas são de diferentes fabricantes e espessuras. Na Figura 7 têm-se duas amostras ensaiadas sob contrapiso.

Polipropileno expandido (EPP): a resina de polipropileno é combinada com outros ingredientes, para depois ser expandida. As principais características são:

(a) alta resistência a impactos;

(b) resistência química; e

(c) leveza.

O material é encontrado em rolos (bobina $0,63 \mathrm{~m}$ x $50 \mathrm{~m}$ ). Na Figura 8 observa-se a amostra de $2 \mathrm{~mm}$ ensaiada sob contrapiso.

Polietileno expandido (EPE): é um termoplástico, derivado do etileno, quimicamente resistente, expandido ao ser submetido ao processo de extrusão, deixando-o com uma característica espumosa. O material é encontrado em rolos. A Figura 9 traz dois modelos ensaiados.

Borracha reciclada: grânulos de pneus reciclados, aglomerados com poliuretano. O material é encontrado em rolos. Na Figura 10 podem ser vistos dois modelos ensaiados.

Em alguns casos foram testados mais de um material para o mesmo grupo, como visto nas imagens mostradas nas Figuras 3, 5 e 6, as quais podem ser do mesmo fabricante com espessuras distintas, ou de fabricantes diferentes e mesma espessura.

\section{Procedimentos e parâmetros}

A ISO 16283-2 (INTERNATIONAL..., 2020a) estabelece o procedimento-padrão para medição de nível de pressão sonora de acordo com:

(a) posições de fonte de impacto; posições de microfone fixo;

(b) medição de ruído de fundo; e

(c) medição de tempo de reverberação, considerando transmissões secundárias, visto que a laje teste possui vínculo rígido com a estrutura da câmara de recepção. 
Figura 7 - Manta de lã de poliéster, amostra (a) de $8 \mathrm{~mm}$, e (b) de $10 \mathrm{~mm}$ sob contrapiso

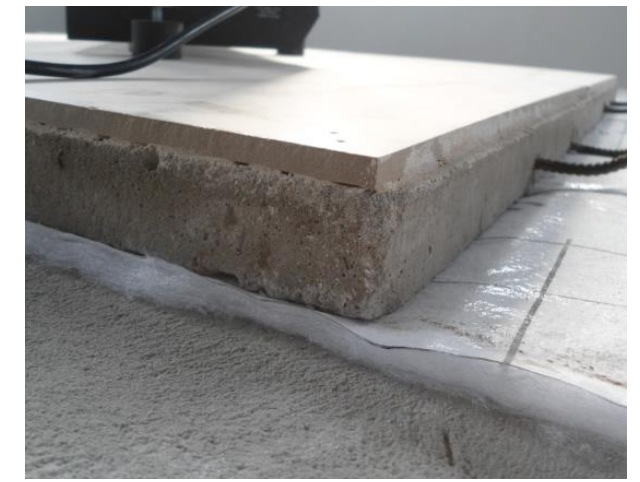

(a)

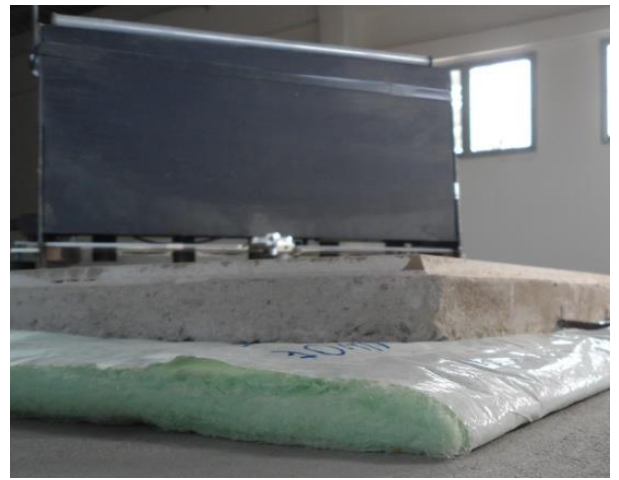

(b)

Figura 8 - Manta de polipropileno expandido $2 \mathrm{~mm}$ sob contrapiso

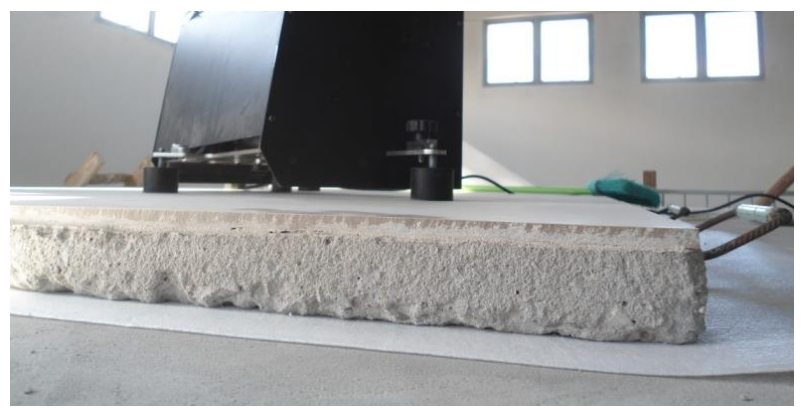

Figura 9 - Manta de polietileno, amostra (a) de $5 \mathrm{~mm}$, e (b) de $10 \mathrm{~mm}$ sob contrapiso

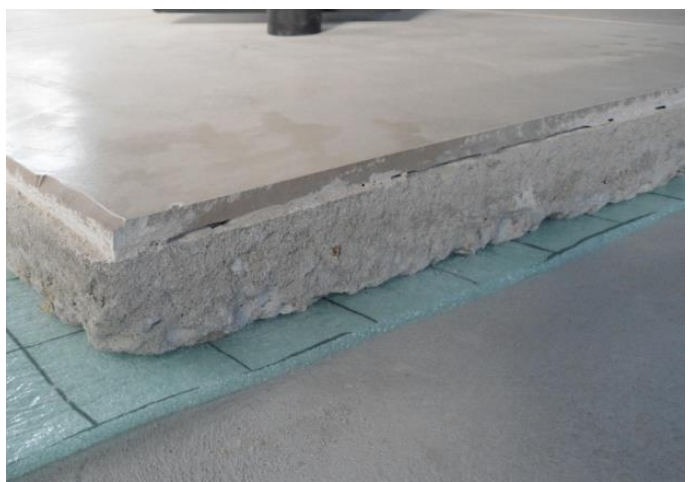

(a)

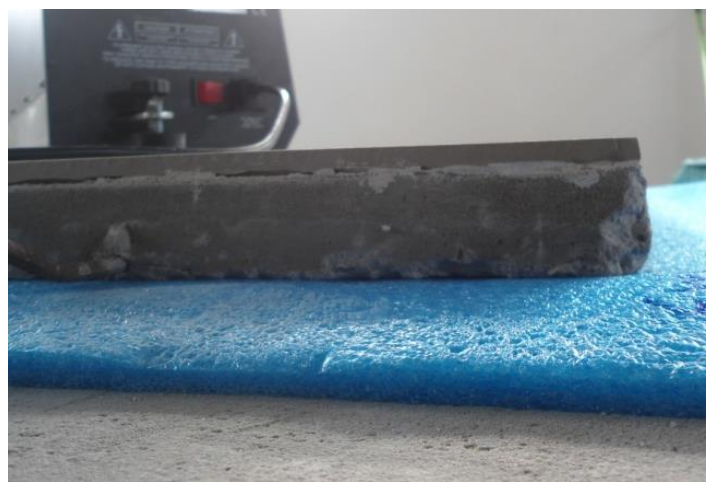

(b)

Figura 10 - Manta de borracha reciclada, amostra (a) de $5 \mathrm{~mm}$, e (b) de $8 / 4 \mathrm{~mm}$ sob contrapiso

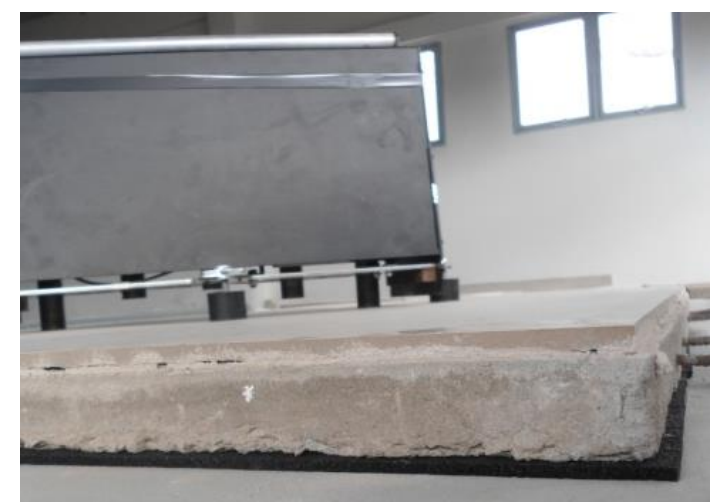

(a)

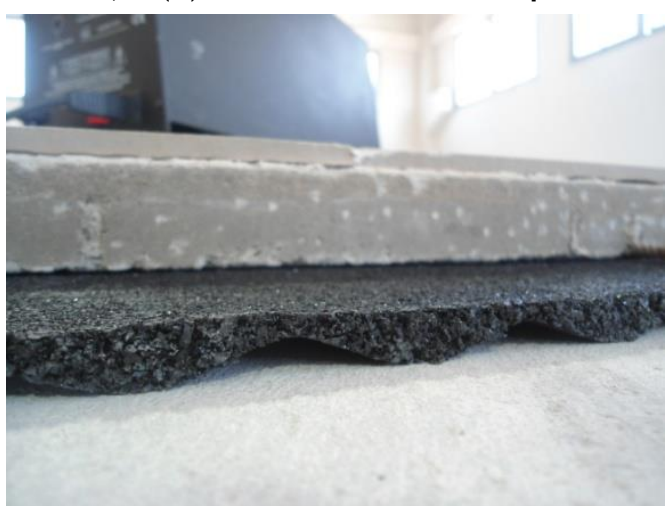

(b)

112 Haas, A.; Lourenço, W. M. de; Santos, J. C. P. dos; Santos, J. L. P. dos 
O tempo de reverberação na sala de recepção foi medido usando o método de ruído interrompido, com duas posições para o alto-falante e três posições para microfone com alturas distintas: $1(1,30 \mathrm{~m}), 2(1,90 \mathrm{~m})$ e 3 $(2,30 \mathrm{~m})$, fazendo-se duas medições para cada posição de microfone, conforme parâmetros estabelecidos pela NBR ISO 3382-2 (ABNT, 2017). Na Figura 11, tem-se o croqui dos posicionamentos.

Para a medição do nível de ruído residual e do nível de pressão sonora de ruído de impacto, determinam-se quatro posições de máquina de impacto, distribuídas conforme a Figura 12(a), respeitando a distância de 0,5 $\mathrm{m}$ das arestas do piso e o posicionamento da linha de martelos a $45^{\circ}$ em relação à posição das vigotas.

Quanto aos microfones, foram utilizadas quatro posições de microfone com alturas diferentes: A (1,20 m), B $(1,60 \mathrm{~m}), \mathrm{C}(2,10 \mathrm{~m})$ e $\mathrm{D}(1,50 \mathrm{~m})$, realizando-se duas medições para cada posição de microfone. A Figura 12(b) traz o posicionamento dos microfones.

Após obtenção dos dados utilizando os procedimentos descritos, faz-se o tratamento dos valores finais de nível de pressão sonora padronizado $\left(L_{n T}^{\prime}\right)$ conforme ISO 717-2 (INTERNATIONAL..., 2020b), de modo a definir um valor único de $L_{n T, w}^{\prime}$, que expresse o desempenho acústico do sistema ensaiado em $\mathrm{dB}$.

Após as medições realizadas na câmara de recepção, para cada posição da máquina de impacto, tem-se a determinação do nível de pressão sonora média $\left(L_{i}\right)$, que é a média logarítmica energética para as diferentes posições de microfone, para cada posição de máquina de impacto, conforme a Equação 1.

$\mathrm{L}_{\mathrm{i}}=10 \lg \left(\frac{1}{\mathrm{n}} \sum_{\mathrm{j}=1}^{\mathrm{n}} 10^{\mathrm{Lj} / 10}\right)$

Eq. 1

Figura 11 - Posicionamento da fonte e microfones para avaliação do TR (distâncias em centímetros)
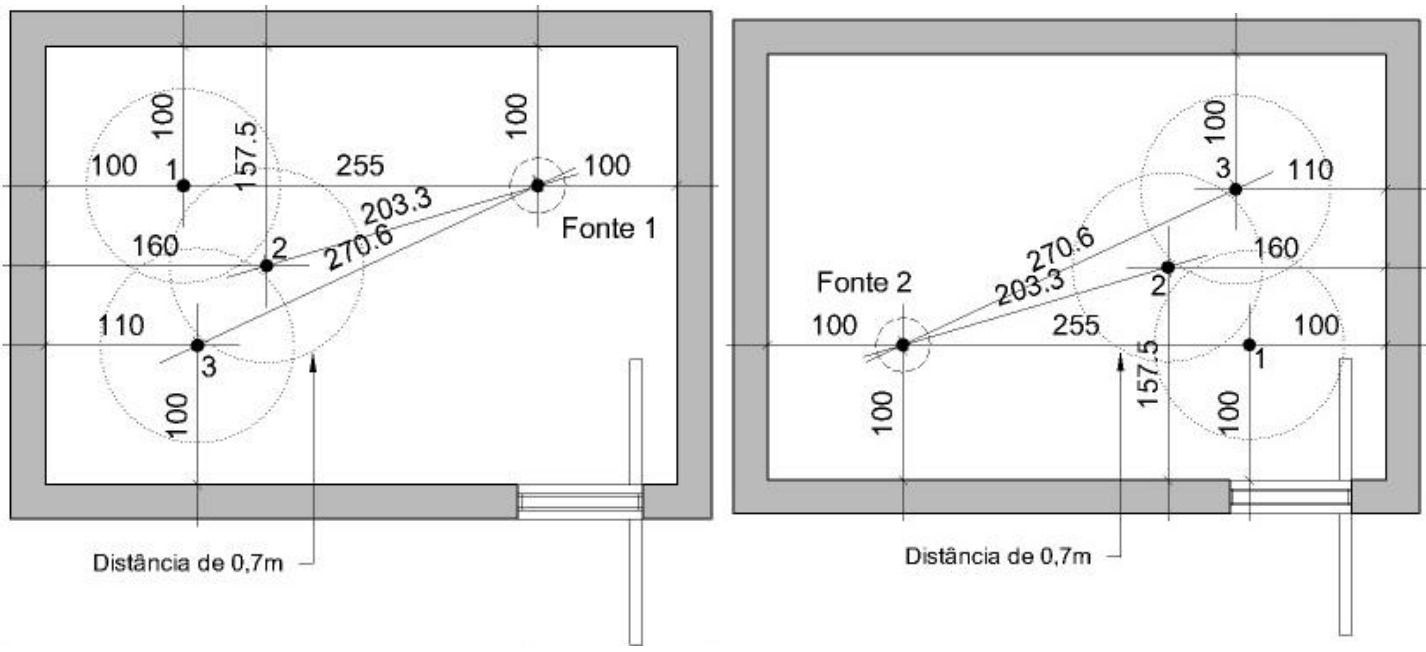

Figura 12 - Posicionamento da máquina de impacto (a), e posicionamento dos microfones (b), para avaliação do nível de pressão sonora

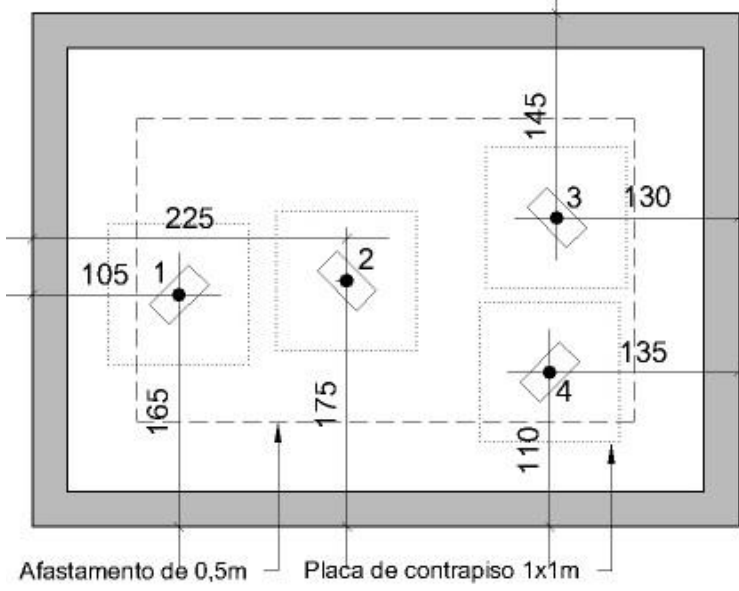

(a)

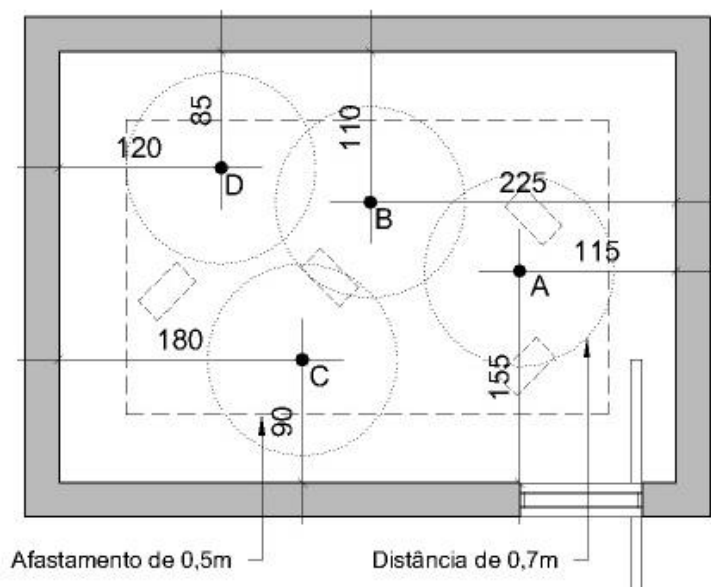

(b) 
O nível de pressão sonora de impacto padronizado $\left(L_{n T}^{\prime}\right)$ é o nível de pressão sonora $(L i)$ corrigido, dado em decibel, sendo dez vezes o logaritmo comum da razão do tempo de reverberação medido, $T$, para o tempo de reverberação de referência, $T_{0}$, calculado para cada posição de máquina de impacto, conforme a Equação 2.

$\mathrm{L}_{\mathrm{nT}}^{\prime}=\mathrm{L}_{\mathrm{i}}-10 \lg \frac{\mathrm{T}}{\mathrm{T}_{0}}$

Eq. 2

Por fim, calcula-se o nível de pressão sonora de impacto padronizado médio $\left(L_{n T}^{\prime}\right)$ da amostra, conforme a Equação 3.

$\mathrm{L}_{\mathrm{nT}}^{\prime}=10 \lg \left(\frac{1}{\mathrm{~m}} \sum_{\mathrm{j}=1}^{\mathrm{m}} 10^{\mathrm{L}_{\mathrm{nTj}}^{\prime} / 10}\right)$

Já a obtenção do número único de isolamento de impacto, ou seja, o nível de pressão sonora de impacto padronizado ponderado $\left(L_{n T, w}^{\prime}\right)$, utiliza um método de comparação, para avaliar o resultado de uma medição do nível de pressão sonora de impacto padronizado médio $\left(L_{n T}^{\prime}\right)$ de uma amostra, com a curva de referência dada pela ISO 717-2 (INTERNATIONAL..., 2020b).

Para a realização da ponderação, deve-se deslocar a curva de referência em quantidades de $1 \mathrm{~dB}$ até que a soma dos desvios desfavoráveis (valores acima da curva de referência) seja o maior possível, porém sem ultrapassar $32 \mathrm{~dB}$. Após o deslocamento da curva de acordo com o procedimento, o valor único em decibel é o ponto no qual a curva de referência deslocada encontra a reta de $500 \mathrm{~Hz}$. A Figura 13 traz um exemplo do deslocamento da curva de referência, destacando os desvios desfavoráveis acima da curva de referência deslocada e o ponto que determina o valor de $L_{n T, w}^{\prime}$ na faixa de $500 \mathrm{~Hz}$.

\section{Resultados e discussões}

Os resultados obtidos por meio das medições são apresentados em forma de gráfico, com os valores de nível de pressão sonora padronizado médio $\left(L_{n T}^{\prime}\right)$ por faixa de frequência em bandas de terço de oitava. A obtenção do valor único de nível de pressão sonora padronizado ponderado $\left(L_{n T, w}^{\prime}\right)$ segue os parâmetros da ISO 717-2 (INTERNATIONAL..., 2020b).

\section{Análise das amostras de referência}

Este item contempla a análise individual dos resultados das amostras de referência, enumeradas no Quadro 4, juntamente com informações de configuração de montagem e espessura final.

A comparação entre os desempenhos das amostras de referência permite a compreensão do funcionamento das diferentes camadas do sistema construtivo.

O gráfico da Figura 14 mostra a variação do nível de pressão sonora padronizado médio $L_{n T}^{\prime}$ em função de faixas de frequência.

Figura 13 - Exemplo de deslocamento da curva de referência

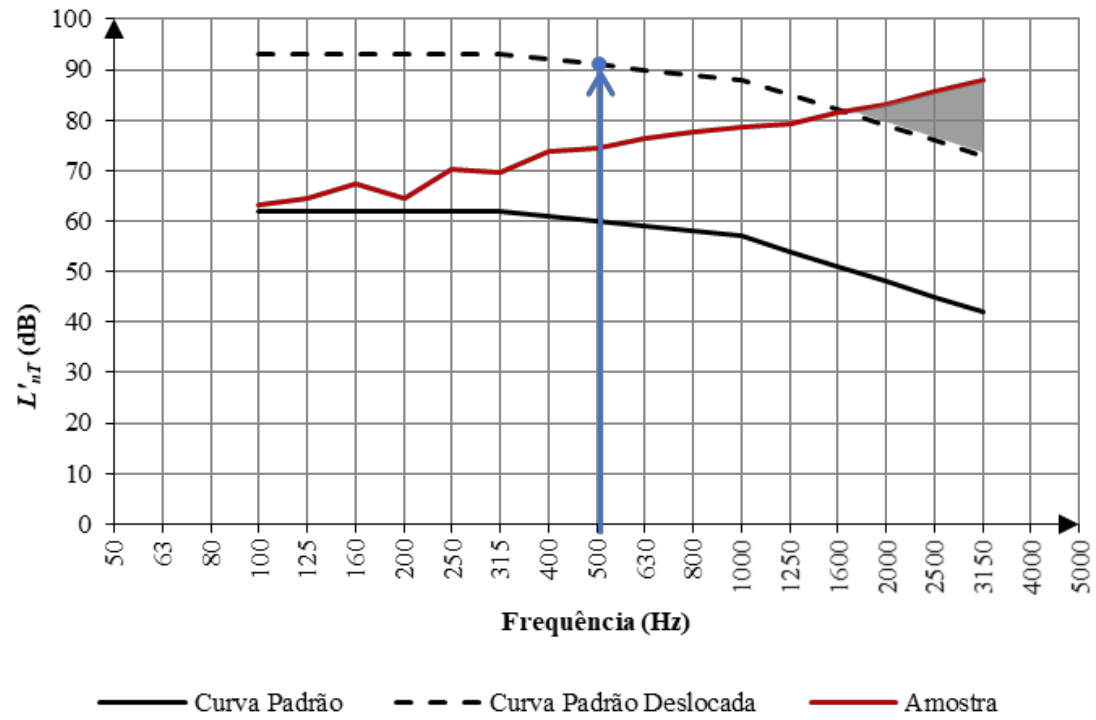

114 Haas, A.; Lourenço, W. M. de; Santos, J. C. P. dos; Santos, J. L. P. dos 
Quadro 4 - Amostras de referência

\begin{tabular}{|c|l|c|}
\hline Amostra & \multicolumn{1}{|c|}{ Composição } & Altura \\
\hline $\mathbf{1}$ & Laje em osso & $13,5 \mathrm{~cm}$ \\
\hline $\mathbf{2}$ & Laje + contrapiso $(4 \mathrm{~cm})$ & $17,5 \mathrm{~cm}$ \\
\hline $\mathbf{3}$ & Laje + contrapiso $(4 \mathrm{~cm})+$ revestimento cerâmico & $18,5 \mathrm{~cm}$ \\
\hline
\end{tabular}

Figura 14 - Comparação do desempenho acústico das amostras de referência

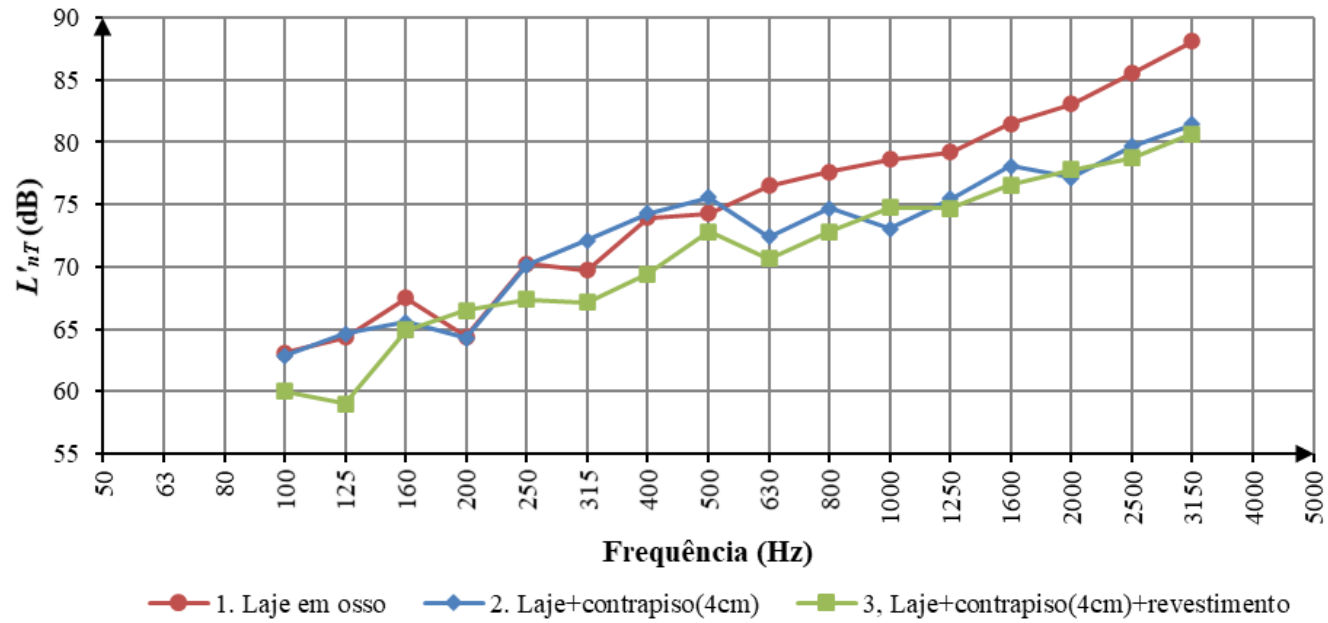

Observa-se que as curvas demonstram o mesmo comportamento crescente. Os valores apresentam oscilações até a faixa de frequência de $250 \mathrm{~Hz}$, visto que são nessas frequências que são encontradas as frequências de ressonância mecânicas, influenciadas pela resiliência dos materiais (PAIXÃO, 2002). A amostra 2 possui um desvio em relação à amostra 1 na faixa de $250 \mathrm{~Hz}$ a $500 \mathrm{~Hz}$. Trata-se de uma resposta vibracional do painel não homogêneo (OLIVEIRA; PATRÍCIO, 2017).

Após essa faixa, o ganho no isolamento das amostras 2 e 3 é significativo, seguindo os preceitos do isolamento referente ao ganho de massa (lei da massa). A amostra 3, quando comparada à amostra 2, possui isolamento maior em baixa frequência, e nas frequências de $200 \mathrm{~Hz}, 1 \mathrm{kHz}$ e $2 \mathrm{kHz}$ ocorrem oscilações, provenientes da densidade superficial do revestimento de piso, que não é eficiente para ruído de impacto, e dependendo do tipo de queima chega a uma densidade superior a $2 \mathrm{~g} / \mathrm{cm}$ (CONTARTESI, 2015).

Na Figura 15, tem-se a comparação entre os resultados de $L_{n T, w}^{\prime}$ das amostras com os níveis de desempenho definidos pela NBR 15575-3 (ABNT, 2013), de modo a classificá-los perante o critério que leva em consideração o sistema de piso, separando unidades habitacionais autônomas.

Nota-se que o $L_{n T, w}^{\prime}$ da laje em osso (amostra 1) está muito acima do nível mínimo de $80 \mathrm{~dB}$ indicado pela norma. Com a adição do contrapiso de $4 \mathrm{~cm}$ (amostra 2), percebe-se uma melhora de $7 \mathrm{~dB}$. Já o acréscimo de $1 \mathrm{~cm}$ do revestimento cerâmico sobre o contrapiso (amostra 3) aumenta o isolamento em $1 \mathrm{~dB}$.

Mesmo havendo melhora no desempenho, com o aumento da espessura do sistema, nenhuma das configurações atinge o nível mínimo exigido pela NBR 15575-3 (ABNT, 2013) de $L_{n T, w}^{\prime} \leq 80 \mathrm{~dB}$. Portanto, a tipologia construtiva com vigota pré-moldada protendida, contrapiso $4 \mathrm{~cm}$ e revestimento cerâmico necessita de tratamento acústico para se enquadrar na normativa brasileira, pois se trata de uma composição heterogênea (possui cheios e vazios), o que possibilita uma resposta vibracional mais acentuada.

\section{Análise das amostras de piso flutuante}

Esta seção abrange a análise dos resultados das amostras de piso flutuante, dividida por grupos conforme o tipo de material resiliente. Para melhor compreender a eficiência do sistema de piso flutuante, seus resultados serão comparados com os resultados da amostra de referência 3 (laje + contrapiso $(4 \mathrm{~cm})+$ revestimento cerâmico).

A configuração dos ensaios de piso flutuante seguiu a montagem apresentada na Figura 16, no qual o material resiliente é colocado entre a laje e a placa de contrapiso com revestimento cerâmico. 
Figura 15 - Comparação dos valores de $L_{n T, w}$ das amostras de referência com o critério para sistema de piso separando unidades autônomas

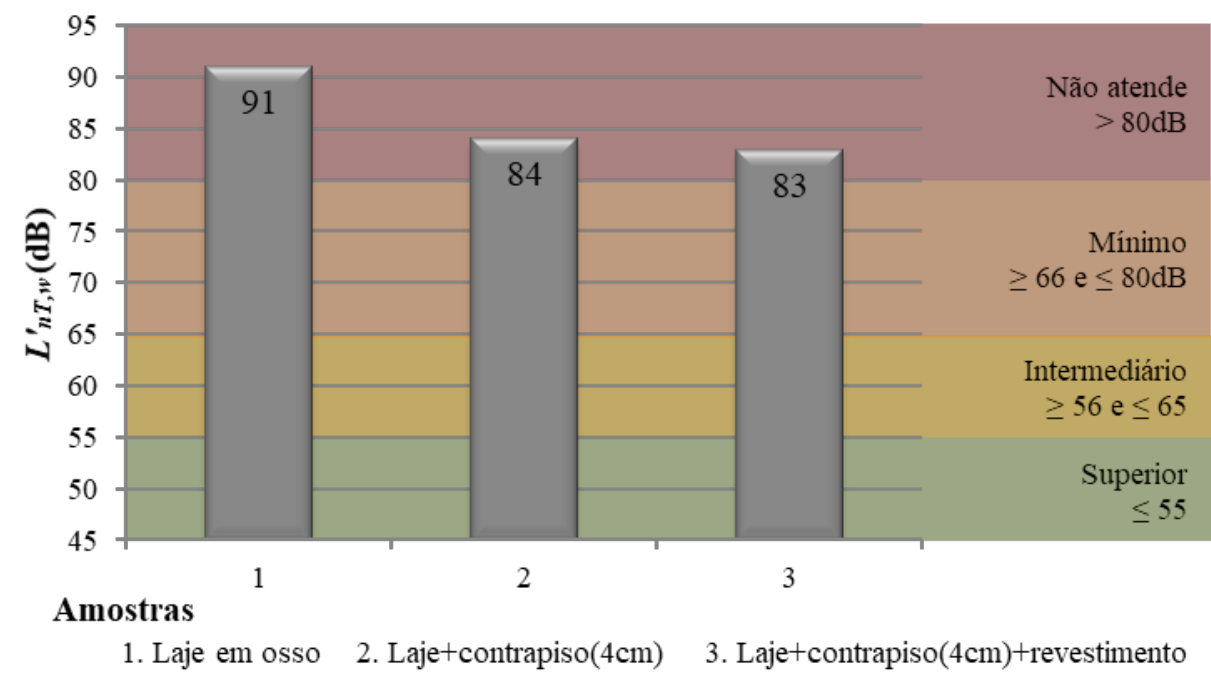

Figura 16 - Modelo de montagem

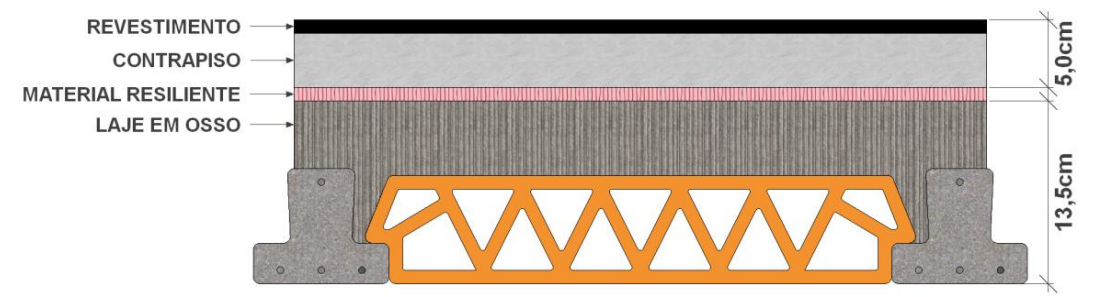

A Tabela 2 contém as amostras de piso flutuante, enumeradas e divididas conforme o grupo do material resiliente utilizado na composição do sistema, contendo as informações de densidade e espessura do material, fornecidas pelos fabricantes.

Observa-se que existem, em um mesmo grupo de materiais resilientes, espessuras duplicadas. Isso ocorre devido aos materiais serem de fabricantes diferentes.

Comparando os desempenhos dos sistemas de piso flutuante com diferentes materiais resilientes, é possível corroborar como o conjunto atua no sistema construtivo. A Figura 17 apresenta o gráfico com a variação do nível de pressão sonora padronizado médio $L_{n T}^{\prime}$ em função de faixas de frequência de cada sistema de piso flutuante, em que as amostras estão divididas por cores, conforme o tipo de material resiliente, os valores de $L_{n T}^{\prime}$ podem ser vistos na Tabela 3 .

Ao observar o gráfico, fica evidente que há perda no isolamento, principalmente nas faixas de frequências de $200 \mathrm{~Hz}$ e $500 \mathrm{~Hz}$, em todas as amostras, que podem ser provenientes do amortecimento da camada resiliente, na região das ressonâncias mecânicas.

Os sistemas de piso flutuante com manta de lã de vidro (amostra 4) e lã de PET (amostras 5 a 10) preenchem a parte inferior do gráfico. O sistema com lã de vidro geralmente possui o melhor desempenho; entretanto, o sistema com a amostra 10, lã de PET $10 \mathrm{~mm}$, teve um desempenho similar, com uma performance inferior ao sistema com lã de vidro em baixa frequência, mas que se iguala nas médias frequências e ultrapassa em alta frequência, obtendo um resultado final superior.

Entretanto, corrobora-se que as amostras possuem densidades superficiais e espessuras distintas, caracterizando comportamentos de isolamento, também diferentes. Os demais sistemas com lã de PET também possuem um bom desempenho, ficando próximos ao sistema com lã de vidro em alta frequência.

No sistema de piso flutuante, com manta de borracha reciclada ondulada 8/4 mm (amostra 18), o desempenho destaca-se devido à forma ondulada da base da manta, tendo $8 \mathrm{~mm}$ na parte maior da ondulação e $4 \mathrm{~mm}$ na parte menor, o que aumenta o efeito de mola do sistema.

116 Haas, A.; Lourenço, W. M. de; Santos, J. C. P. dos; Santos, J. L. P. dos 
Tabela 2 - Materiais resilientes

\begin{tabular}{l|c|c|c}
\hline \multicolumn{1}{c|}{ Material } & Amostra & Densidade & Espessura \\
\hline Lã de vidro & 4 & $60 \mathrm{~kg} / \mathrm{m}$ & $15 \mathrm{~mm}$ \\
\hline & 5 & $30 \mathrm{~kg} / \mathrm{m}$ & $8 \mathrm{~mm}$ \\
& 6 & $36 \mathrm{~kg} / \mathrm{m}$ & $8 \mathrm{~mm}$ \\
Lã de poliéster (PET) & 7 & $80 \mathrm{~kg} / \mathrm{m}$ & $5 \mathrm{~mm}$ \\
& 8 & $60 \mathrm{~kg} / \mathrm{m}$ & $4 \mathrm{~mm}$ \\
& 9 & $60 \mathrm{~kg} / \mathrm{m}$ & $5 \mathrm{~mm}$ \\
\hline Polipropileno expandido (EPP) & 10 & $60 \mathrm{~kg} / \mathrm{m}$ & $10 \mathrm{~mm}$ \\
\hline & 11 & $42 \mathrm{~kg} / \mathrm{m}$ & $2 \mathrm{~mm}$ \\
Polietileno expandido (EPE) & 13 & $20 \mathrm{~kg} / \mathrm{m}$ & $5 \mathrm{~mm}$ \\
& 14 & $25 \mathrm{~kg} / \mathrm{m}$ & $5 \mathrm{~mm}$ \\
& 15 & $65 \mathrm{~kg} / \mathrm{m}$ & $10 \mathrm{~mm}$ \\
Borracha reciclada & 16 & $700 \mathrm{~kg} /$ & $5 \mathrm{~mm}$ \\
\hline
\end{tabular}

Figura 17 - Comparação do desempenho acústico ao ruído de impacto das amostras

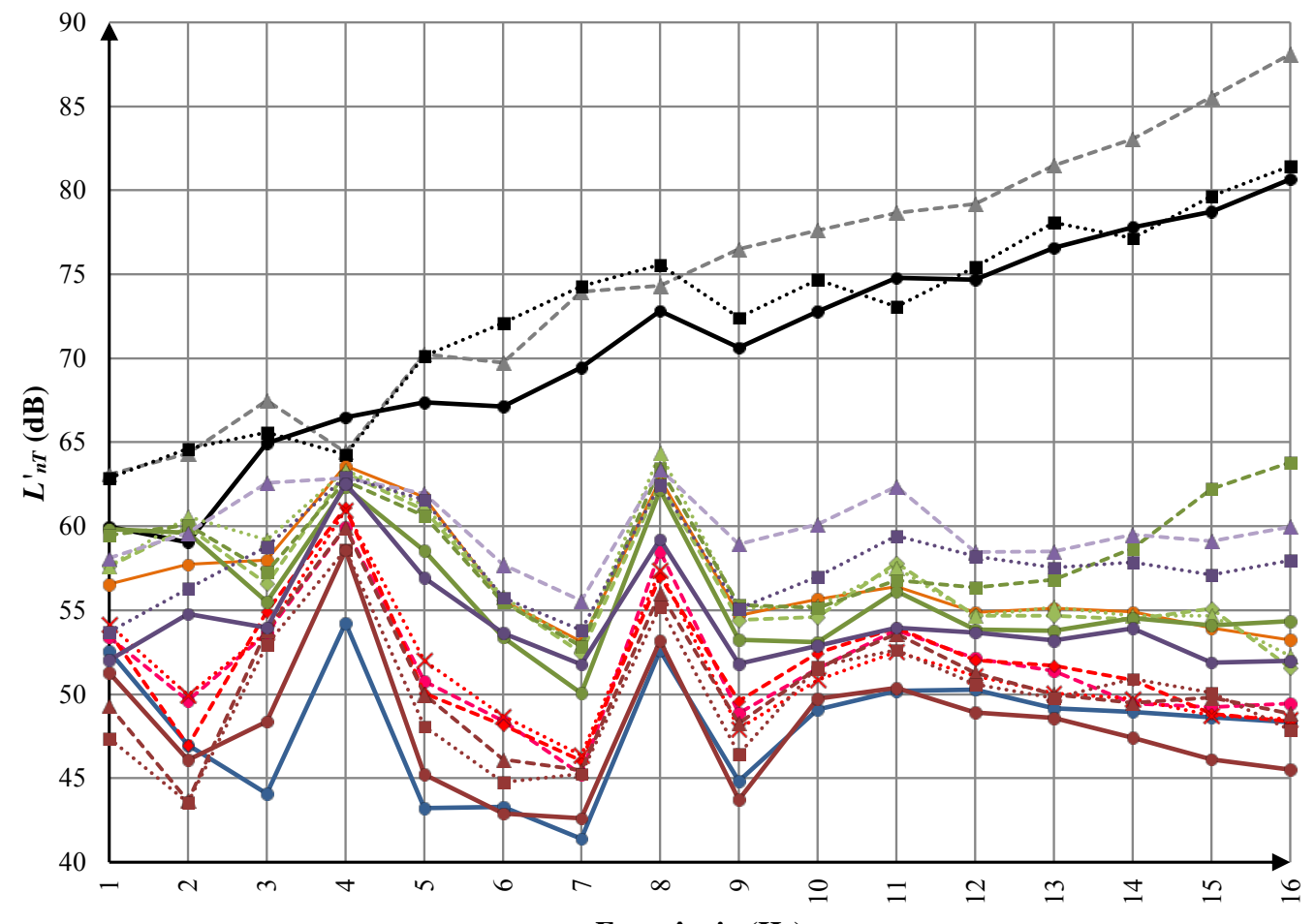

Amostras

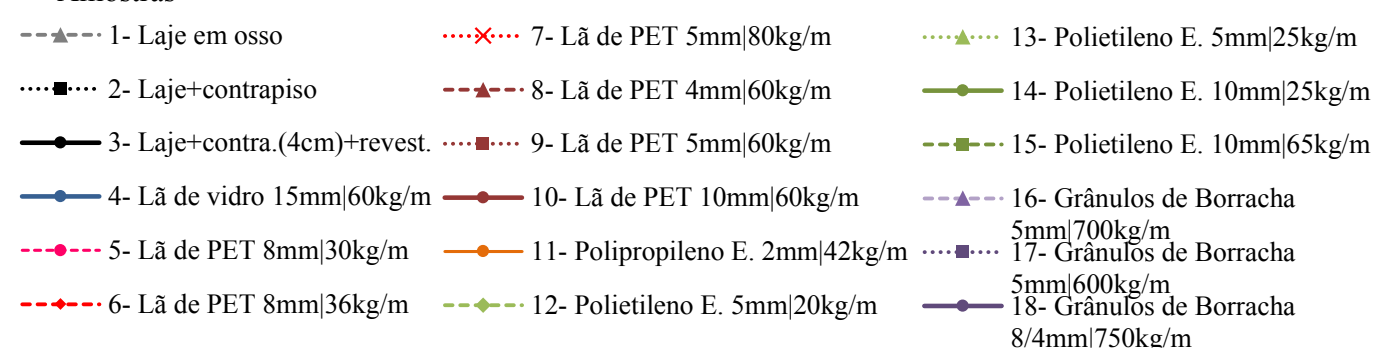


Tabela 3 - Tabela com valores de $L_{n T}$ da Figura 17 - comparação do desempenho acústico ao ruído de impacto das amostras

\begin{tabular}{|c|c|c|c|c|c|c|c|c|c|c|c|c|c|c|c|c|}
\hline$f(\mathrm{~Hz})$ & 100 & 125 & 160 & 200 & 250 & 315 & 400 & 500 & 630 & 800 & $1 \mathrm{k}$ & $1,25 \mathrm{k}$ & $1,6 \mathrm{k}$ & $2 k$ & $2,5 \mathrm{k}$ & $3,15 \mathrm{k}$ \\
\hline L'nT 1 & 63 & 64 & 67 & 64 & 70 & 70 & 74 & 74 & 77 & 78 & 79 & 79 & 81 & 83 & 83 & 88 \\
\hline L'nT 2 & 63 & 65 & 66 & 64 & 70 & 72 & 74 & 76 & 72 & 75 & 73 & 75 & 78 & 77 & 80 & 81 \\
\hline L'nT 3 & 60 & 59 & 65 & 66 & 67 & 67 & 69 & 73 & 71 & 73 & 75 & 75 & 77 & 78 & 79 & 81 \\
\hline L'nT 4 & 53 & 47 & 44 & 54 & 43 & 43 & 41 & 53 & 45 & 49 & 50 & 50 & 49 & 49 & 49 & 48 \\
\hline L'nT 5 & 53 & 50 & 54 & 60 & 51 & 48 & 45 & 59 & 49 & 52 & 54 & 52 & 51 & 49 & 49 & 49 \\
\hline L'nT 6 & 54 & 47 & 55 & 61 & 50 & 48 & 46 & 57 & 50 & 52 & 54 & 52 & 52 & 51 & 49 & 48 \\
\hline L'nT 7 & 54 & 50 & 54 & 61 & 52 & 49 & 46 & 57 & 48 & 51 & 53 & 51 & 50 & 50 & 49 & 49 \\
\hline L'nT 8 & 49 & 44 & 54 & 60 & 50 & 46 & 45 & 56 & 48 & 52 & 54 & 51 & 50 & 49 & 50 & 49 \\
\hline L'nT 9 & 47 & 44 & 53 & 59 & 48 & 45 & 45 & 55 & 46 & 52 & 53 & 51 & 50 & 51 & 50 & 48 \\
\hline L'nT 10 & 51 & 46 & 48 & 59 & 45 & 43 & 43 & 53 & 44 & 50 & 50 & 49 & 49 & 47 & 46 & 46 \\
\hline L'nT 11 & 57 & 58 & 58 & 64 & 62 & 56 & 53 & 63 & 55 & 56 & 56 & 55 & 55 & 55 & 54 & 53 \\
\hline L'nT 12 & 58 & 60 & 57 & 63 & 61 & 56 & 52 & 63 & 54 & 55 & 58 & 55 & 55 & 54 & 55 & 52 \\
\hline L'nT 13 & 58 & 61 & 59 & 63 & 61 & 56 & 53 & 64 & 55 & 55 & 58 & 55 & 55 & 55 & 55 & 52 \\
\hline L'nT 14 & 60 & 60 & 55 & 62 & 59 & 53 & 50 & 62 & 53 & 53 & 56 & 54 & 54 & 55 & 54 & 54 \\
\hline L'nT 15 & 59 & 60 & 57 & 63 & 61 & 55 & 53 & 63 & 55 & 55 & 57 & 56 & 57 & 59 & 62 & 64 \\
\hline L'nT 16 & 58 & 60 & 63 & 63 & 62 & 58 & 56 & 63 & 59 & 60 & 62 & 58 & 58 & 60 & 59 & 60 \\
\hline L'nT 17 & 54 & 56 & 59 & 63 & 62 & 56 & 54 & 62 & 55 & 57 & 59 & 58 & 58 & 58 & 57 & 58 \\
\hline L'n'T 18 & 52 & 55 & 54 & 63 & 57 & 54 & 52 & 59 & 52 & 53 & 54 & 54 & 53 & 54 & 52 & 52 \\
\hline
\end{tabular}

$\mathrm{Na}$ parte superior do gráfico estão os sistemas de piso flutuante com mantas de polipropileno expandido (EPP, amostra 11) e polietileno expandido (EPE, amostras 12 a 15), os quais possuem curvas semelhantes e o mesmo $L_{n T, w}^{\prime}$. Destaca-se que o desempenho do sistema com polipropileno inicialmente é melhor em relação ao sistema com polietileno, em seguida as curvas seguem próximas.

$\mathrm{Na}$ parte superior do gráfico estão os sistemas de piso flutuante com mantas de borracha reciclada de $5 \mathrm{~mm}$ (amostras 16 e 17), que em grande parte acompanham as curvas dos sistemas de EPP (amostra 11) e EPE (amostras 12 a 15), mas em alta frequência o desempenho é inferior a esses materiais, devido à rigidez do material.

O comparativo e a classificação dos resultados $L_{n T, w}^{\prime}$ das amostras, com os níveis definidos pela NBR 15575-3 (ABNT, 2013), para o critério que leva em consideração o sistema de piso separando unidades habitacionais autônomas, podem ser vistos na Figura 18.

Verifica-se que a maior parte dos sistemas de piso flutuante encontra-se no nível intermediário ( $56 \leq L_{n T, w}^{\prime} \geq$ $65 \mathrm{~dB})$, tem-se uma amostra no nível mínimo $\left(66 \leq L_{n T, w}^{\prime} \geq 80 \mathrm{~dB}\right)$, e duas no nível superior $(\leq 55 \mathrm{~dB})$.

Os sistemas com mantas de lã de PET (amostras 5 a 9) classificados no nível intermediário possuem um bom desempenho e ficam próximos ao nível superior com $L_{n T, w}^{\prime}$ de $56 \mathrm{~dB}$ e $57 \mathrm{~dB}$, a amostra 10 com lã de PET atinge o nível superior com $L_{n T, w}^{\prime}$ de $54 \mathrm{~dB}$, junto com o sistema da amostra 4 com lã de vidro, que apresenta $L_{n T, w}^{\prime}$ igual a $55 \mathrm{~dB}$.

Por conseguinte, as amostras 4 e 10 apresentam espessuras consideráveis, em relação às demais amostras, com densidade superficial de $60 \mathrm{~kg} / \mathrm{m}$, visto que não são demasiadamente rígidas, favorecendo o sistema massa-mola-massa para atenuação das vibrações estruturais do ruído de impacto.

Já os sistemas com polipropileno expandido (EPP, amostra 11) e polietileno expandido (EPE, amostras 12 a 14) estão centralizadas no nível intermediário com $L_{n T, w}^{\prime}$ de $61 \mathrm{~dB}$, com exceção da amostra 15 , que, devido à densidade superficial do material resiliente, fica no nível mínimo, porém muito próxima ao intermediário com $L_{n T, w}^{\prime}$ de $66 \mathrm{~dB}$. 
Figura 18 - Comparação dos resultados de $L_{n T, w}^{\prime}$ das amostras com o critério para sistema de pisos separando unidades autônomas

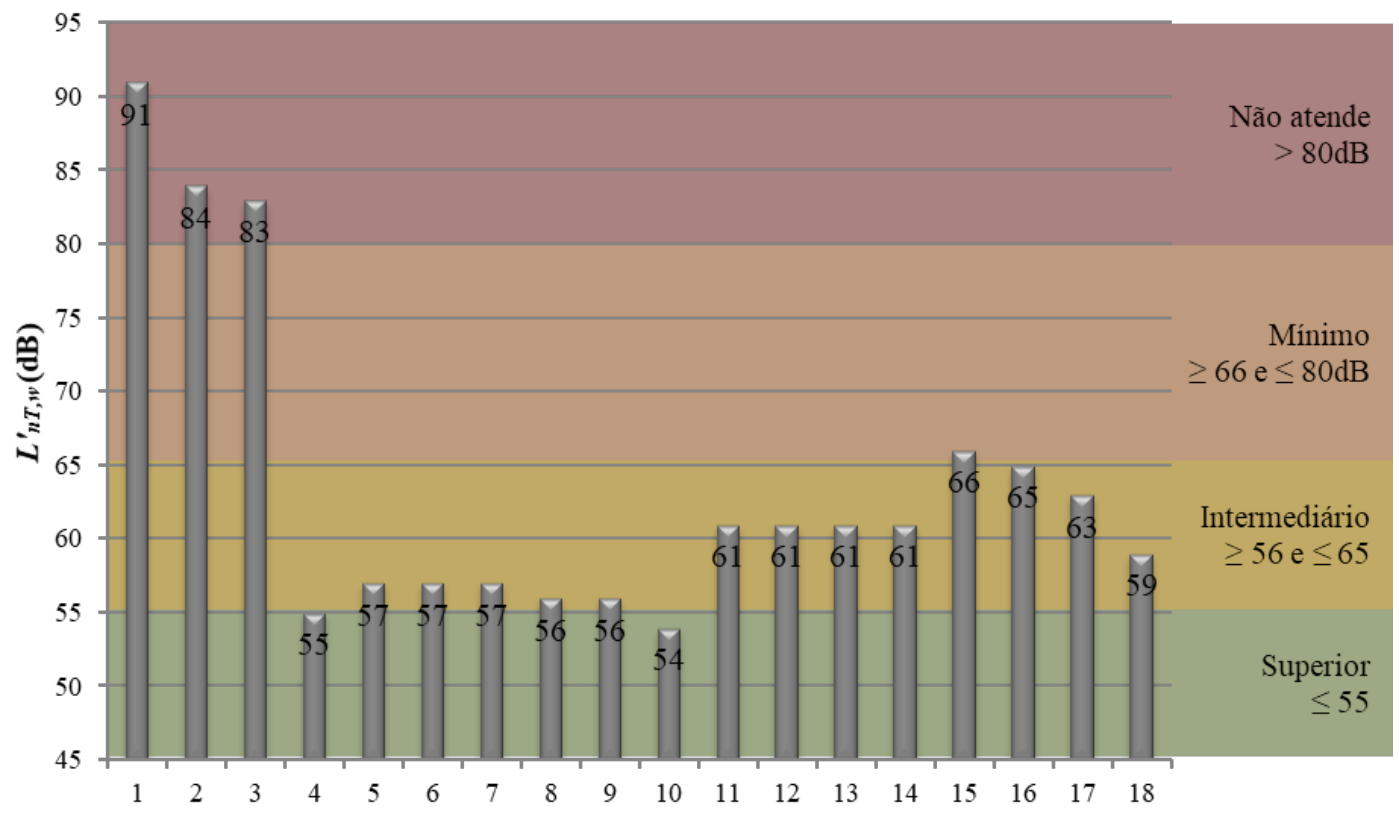

Amostras

1- Laje em osso
2- Laje+contrapiso $(4 \mathrm{~cm})$
3- Laje+contrapiso $(4 \mathrm{~cm})+$ revest.
4- Lã de vidro $15 \mathrm{~mm} \mid 60 \mathrm{~kg} / \mathrm{m}^{3}$
5- Lã de PET $8 \mathrm{~mm} \mid 30 \mathrm{~kg} / \mathrm{m}^{3}$
6- Lã de PET $8 \mathrm{~mm} \mid 36 \mathrm{~kg} / \mathrm{m}^{3}$

\begin{abstract}
7- Lã de PET $5 \mathrm{~mm} \mid 80 \mathrm{~kg} / \mathrm{m}^{3}$
8- Lã de PET $4 \mathrm{~mm} \mid 60 \mathrm{~kg} / \mathrm{m}^{3}$

9- Lã de PET $5 \mathrm{~mm} / 60 \mathrm{~kg} / \mathrm{m}^{3}$

10- Lã de PET $10 \mathrm{~mm} / 60 \mathrm{~kg} / \mathrm{m}^{3}$

11- EPP $2 \mathrm{~mm} \mid 42 \mathrm{~kg} / \mathrm{m}^{3}$

12- EPE $5 \mathrm{~mm} / 20 \mathrm{~kg} / \mathrm{m}^{3}$
\end{abstract}

\author{
13- EPE $5 \mathrm{~mm} \mid 25 \mathrm{~kg} / \mathrm{m}^{3}$ \\ 14- EPE $10 \mathrm{~mm} \mid 25 \mathrm{~kg} / \mathrm{m}^{3}$ \\ 15- EPE $10 \mathrm{~mm} / 65 \mathrm{~kg} / \mathrm{m}^{3}$ \\ 16- Grânulos de borracha $5 \mathrm{~mm} / 700 \mathrm{~kg} / \mathrm{m}^{3}$ \\ 17- Grânulos de borracha $5 \mathrm{~mm} / 600 \mathrm{~kg} / \mathrm{m}^{3}$ \\ 18- Grânulos de borracha $8 / 4 \mathrm{~mm} \mid 750 \mathrm{~kg} / \mathrm{m}^{3}$
}

Por fim, têm-se os sistemas com mantas de borracha reciclada e diferentes valores de $L_{n T, w}^{\prime}$ em razão do formato da base das mantas. Para as amostras 16 e 17 com mantas lisas o $L_{n T, w}^{\prime}$ é de $65 \mathrm{~dB}$ e $63 \mathrm{~dB}$, e o desempenho da amostra 18 com manta ondulada melhora, atingindo um $L_{n T, w}^{\prime}$ de $59 \mathrm{~dB}$, classificando-se no nível intermediário.

Dessa maneira, todos os sistemas de piso flutuante testados, levando-se em consideração o local e a forma como a tipologia de laje nervurada pré-fabricada foi construída, enquadram-se dentro da exigência da NBR 15575-3 (ABNT, 2013), para sistemas de piso separando unidades habitacionais autônomas.

A norma 15575-3 (ABNT, 2013) também apresenta o critério de classificação que leva em consideração sistema de pisos separando áreas de uso coletivo (atividades de lazer e esportivas, como home theater, salas de ginástica, salão de festas, salão de jogos, banheiros e vestiários coletivos, cozinhas e lavanderias coletivas) sobre unidades autônomas, apontando $L_{n T, w}^{\prime}$ mínimo exigido de $51 \mathrm{~dB}$ a $55 \mathrm{~dB}$, nível intermediário de $46 \mathrm{~dB}$ a $50 \mathrm{~dB}$ e superior $\leq 45 \mathrm{~dB}$. Nesse critério somente os sistemas de piso flutuante das amostras 4 com lã de vidro 15 mm e amostra 10 com lã de PET 10 mm alcançam nível mínimo.

\section{Comparativo dos desempenhos das amostras ensaiadas}

Analisando os resultados dos sistemas das amostras de referência com os das amostras de piso flutuante, verificam-se os ganhos no isolamento do sistema construtivo.

No gráfico da Figura 17, que apresenta o comparativo das curvas de desempenho dos sistemas, nota-se que os sistemas de piso flutuante com manta de polipropileno expandido (amostra 11) e polietileno expandido (amostras 12 a 15) em alguns pontos em baixa frequência atingem os mesmos valores das curvas de referência (amostras 1 a 3), bem como os sistemas com borracha reciclada (amostras 16 a 18) possuem valores muito próximos aos das curvas de referência (amostras 1 a 3). A diferença se dá, entre essas amostras e as curvas de referência, em alta frequência, em torno de $20 \mathrm{~dB}$. 
Já o sistema com lã de vidro (amostra 4) na parte mais próxima das curvas de referência (amostras 1 a 3) possui uma diferença de $7 \mathrm{~dB}$, enquanto para os sistemas de piso com lã de PET (amostras 5 a 10) a diferença chega a $3 \mathrm{~dB}$, e a maior diferença em alta frequência chega aos $30 \mathrm{~dB}$.

Ao analisar a Figura 18, que apresenta a classificação dos resultados $L_{n T, w}^{\prime}$ dos sistemas, percebe-se que as curvas de referência (amostras 1 a 3) estão acima do nível mínimo da norma, que, conforme ganham camadas ou espessura, reduzem o valor de $L_{n T, w}^{\prime}$. Dessa maneira, da amostra 1 para amostra 3, o ganho no isolamento fica em $8 \mathrm{~dB}$. No nível mínimo, tem-se a amostra 15 com polietileno expandido que tem um ganho de $17 \mathrm{~dB}$ em relação à amostra 3.

Já o ganho no isolamento em relação à amostra 3 para as amostras classificadas no nível intermediário classifica-se da seguinte forma:

(a) sistemas com uso de EPP (amostra 11), EPE (amostras 12 a 15) chegam a $22 \mathrm{~dB}$ de diferença;

(b) sistemas com borracha (amostras 16 a 18) têm ganhos que variam entre $18 \mathrm{~dB}$ e $24 \mathrm{~dB}$; e

(c) sistemas com lã de PET (amostras 5 a 9), com ganhos de $26 \mathrm{~dB}$ e $27 \mathrm{~dB}$.

Por fim, no nível superior tem-se o sistema da amostra 4 com lã de vidro e da amostra 10 com lã de PET com um ganho no isolamento de $28 \mathrm{~dB}$ e $29 \mathrm{~dB}$, respectivamente, em relação à amostra 3.

\section{Considerações finais}

O ruído de impacto é um dos principais fatores de desconforto entre os usuários de edificações de múltiplos pavimentos, estando relacionado diretamente ao sistema construtivo e aos materiais empregados na construção da edificação. Trata-se de um problema que pode ser solucionado ainda em fase de projeto ao designar o tipo de sistema construtivo e os materiais utilizados. Para tanto, é necessário conhecer as características acústicas das tipologias construtivas e seu desempenho perante a normativa 15575-3 (ABNT, 2013).

A realização dessa pesquisa possibilitou aprofundar o conhecimento, sobre o desempenho acústico do sistema construtivo de laje pré-fabricada nervurada composta de vigota protendida e lajota cerâmica com revestimento de piso cerâmico, e sobre a utilização da técnica de piso flutuante como solução, testando diversos materiais resilientes encontrados no mercado.

Quanto ao desempenho do sistema construtivo, para laje em osso sem regularização ou contrapiso, identificada como amostra 1, obteve-se um $L_{n T, w}^{\prime}$ de $91 \mathrm{~dB}$. Um valor elevado se comparado aos valores encontrados por Pedroso (2007) para laje maciça em osso com $L_{n T, w}^{\prime}$ de $78 \mathrm{~dB}$, ficando evidente como a escolha da tipologia construtiva influencia diretamente na qualidade da edificação e no tipo de solução que será recomendada.

Figura 19 - Gráfico conclusivo de porcentagem de amostras de piso flutuante e seus desempenhos

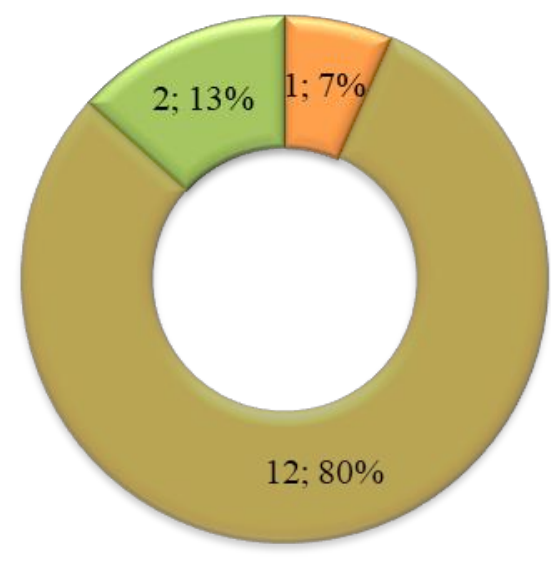

$\square$ Mínimo $\geq 66 \mathrm{e} \leq 80 \mathrm{~dB}$

Intermediário $\geq 56 \mathrm{e} \leq 65$

$\square$ Superior $\leq 55$

120 Haas, A.; Lourenço, W. M. de; Santos, J. C. P. dos; Santos, J. L. P. dos 
A adição do contrapiso de $4 \mathrm{~cm}$ (amostra 2) na composição levou à obtenção de um $L_{n T, w}^{\prime}$ de $84 \mathrm{~dB}, \operatorname{logo} \mathrm{o}$ aumento de espessura propiciou uma melhora no desempenho de $7 \mathrm{~dB}$. E o acréscimo de $1 \mathrm{~cm}$ do revestimento cerâmico (amostra 3) levou a um $L_{n T, w}^{\prime}$ de $83 \mathrm{~dB}$. Mesmo com a melhora no desempenho propiciada pelo aumento da espessura do sistema, nenhuma das configurações para laje pré-fabricada nervurada composta de vigota protendida e lajota cerâmica atinge o nível mínimo exigido pela norma de $L_{n T, w}^{\prime} \leq 80 \mathrm{~dB}$, diferentemente da laje maciça testada por Pedroso (2007) ou Panosso (2015), que mesmo testadas em osso apresentaram desempenho mínimo; no entanto, não significa que o ambiente está confortável acusticamente.

Em relação aos resultados obtidos, utilizando a técnica de piso flutuante, tem-se duas amostras (13\%) com desempenho superior (amostras 9 e 10), uma amostra (7\%) com desempenho inferior (amostra 15), e doze amostras $(80 \%)$ com desempenho intermediário, como pode ser observado no gráfico conclusivo expresso na Figura 19.

Portanto, todos os sistemas de piso flutuante avaliados enquadram-se dentro das exigências da NBR 15575-3 (ABNT, 2013) para o critério de sistema de pisos separando unidades autônomas. Quanto ao critério de sistema de pisos separando áreas de uso coletivo sobre unidades autônomas, somente dois sistemas de piso flutuante alcançaram o nível mínimo exigido $\left(51 \mathrm{~dB} \leq L_{n T, w}^{\prime} \geq 55 \mathrm{~dB}\right.$ ), sistemas com lã de PET $10 \mathrm{~mm}$ (amostra 4) e com lã de vidro 15 mm (amostra 10).

As informações obtidas com a realização dessa pesquisa, tanto para o sistema construtivo quanto para a solução em piso flutuante com materiais resilientes que buscaram melhorar o desempenho da laje finalizada, poderão ser adotadas como respaldo para recomendações e intervenções na construção civil, melhorando a qualidade dos edifícios e a qualidade de vida do usuário, desde que se observe que os resultados podem sofrer alterações devido às diferentes condições do ambiente ensaiado (estrutura, área, volume, vedação, materiais, etc.) conforme colocado por Nunes, Zini e Pagnussat (2014).

\section{Referências}

ASSOCIAÇÃO BRASILEIRA DE NORMAS TÉCNICAS. NBR 15575: edificações habitacionais: desempenho: parte 3: requisitos para os sistemas de pisos. Rio de Janeiro, 2013.

ASSOCIAÇÃO BRASILEIRA DE NORMAS TÉCNICAS. NBR 16313: acústica: terminologia. Rio de janeiro, 2014.

ASSOCIAÇÃO BRASILEIRA DE NORMAS TÉCNICAS. NBR ISO 3382-2: acústica: medição de parâmetros de acústica de salas: parte 2: tempo de reverberação em salas comuns. Rio de Janeiro, 2017.

BISTAFA, S. R. Acústica aplicada ao controle de ruído. 2. ed. São Paulo: Bluncher, 2011.

CARVALHO, R. P. Acústica arquitetônica. 2. ed. Brasília: Thesaurus, 2010.

CONTARTESI, F. Efeitos das condições de queima e densidade aparente sobre a sobrequeima em porcelanatos. São Carlos, 2015. 75 f. Dissertação (Mestrado em Engenharia Civil) - Universidade Federal de São Carlos, São Carlos, 2015.

CORNACCHIA, G.; ROSSI, L.; VIVEIROS, E. B. Medições de isolamento ao ruído de impacto em edificações residenciais. In: ENCONTRO NACIONAL, 10.; ENCONTRO LATINO AMERICANO DE CONFORTO NO AMBIENTE CONSTRUÍDO, 6., Natal, 2009. Proceedings [...] Natal, 2009.

DUARTE, E. de A. C.; VIVEIROS, E. B. Percepção do usuário em relação à qualidade do isolamento acústico - Um estudo de caso em Florianópolis. In: ENCONTRO NACIONAL DE TECNOLOGIA DO AMBIENTE CONSTRUÍDO, 13., Canela, 2010. Anais [...] Canela, 2010.

INTERNATIONAL ORGANIZATION FOR STANDARDIZATION. ISO 140-7: acoustics: measurement of sound insulation in buildings and of building elements: part 7: field measurements of impact sound insulation of floors. Geneve, 1998.

INTERNATIONAL ORGANIZATION FOR STANDARDIZATION. ISO 16283-2: acoustics: field measurement of sound insulation in buildings and of building elements: part 2: impact sound insulation. Geneve, 2020a.

INTERNATIONAL ORGANIZATION FOR STANDARDIZATION. ISO 717-2: acoustics: rating sound insulation in buildings and of building elements: part 2: impact sound insulation. Geneve, $2020 \mathrm{~b}$. 
NUNES, M. F. O.; PATRÍCIO, J. V. Different input parameters in modelling for predicting impact noise of non-homogenus floors. In: INTERNACIONAL CONGRESS ON ACOUSTICS, 22., Buenos Aires, 2016. Proceedings [...] Buenos Aires, 2016.

NUNES, M. F. O.; ZINI, A.; PAGNUSSAT, D. T. Desempenho acústico de sistemas de piso: estudos de caso para isolamento ao ruído aéreo e de impacto. Acústica e Vibrações, v. 46, p. 13-19, dez. 2014.

OLIVEIRA, M. F.; PATRÍCIO, J. V. Impact noise of non-homogeneous floors: analysis of different input parameters for computational modeling predictions. Journal of Civil Engineering and Architecture, v. 1, n. 11, p. 274-281, 2017.

PAIXÃO, D. X. Caracterização do isolamento acústico de uma parede de alvenaria, utilizando análise estatística de energia (SEA). Florianópolis, 2002. 182 f. Tese (Doutorado em Engenharia de Produção) Universidade Federal de Santa Catarina, Florianópolis, 2002.

PANOSSO, A. da S. Avaliação subjetiva do desempenho de soluções de isolamento sonoro ao ruído de impacto. Santa Maria, 2015. 279 f. Dissertação (Mestrado em Engenharia Civil) - Universidade Federal de Santa Maria, Santa Maria, 2015.

PEDROSO, M. A. T. Estudo comparativo entre as modernas composições de pisos flutuantes quanto ao desempenho no isolamento ao ruído de impacto. Santa Maria, 2007. 141 f. Dissertação (Mestrado em Engenharia Civil) - Universidade Federal de Santa Maria, Santa Maria, 2007.

PIERRARD, J. F.; AKKERMAN, D. Manual pro acústica sobre a norma de desempenho: guia prático sobre cada uma das partes relacionadas à área de acústica nas edificações da Norma ABNT NBR 15575:2013 Edificações habitacionais - Desempenho. São Paulo: Rush, 2013.

SEMPRINI, G.; BARBARESI, L. Experimental results of flanking transmission in hollow brick and concrete-slab floor. In: CONFERENCE ON ACOUSTICS, Merano, 2013. Disponível em:

https://www.researchgate.net/publication/303920640_Experimental_Results_of_Flanking_Transmission_in_ Hollow_Brick_and_Concrete-Slab_Floor. Acesso em: 08 abr. 2019.

ZUCHETTO, L. K.; NUNES, M. F. de O.; PATRÍCIO, J. V. Influence of the compression conditions in the acoustic performance of resilient layers of floors. In: INTERNACIONAL CONGRESS ON ACOUSTICS, 22., Buenos Aires, 2016. Proceedings [...] Buenos Aires, 2016. 


\begin{abstract}
Alessandra Haas
Programa de Pós-Graduação em Engenharia Civil | Universidade Federal de Santa Maria | Av. Roraima, 1000, Prédio INPE, Sala 2061, Camobi | Santa Maria - RS - Brasil | CEP 97105-900 | Tel.: (55) 3220-8837 | E-mail: alessandra.compose@gmail.com

Willian Magalhães de Lourenço

Programa de Pós-Graduação em Engenharia Civil | Universidade Federal de Santa Maria | E-mail: creativearquiteto@gmail.com

Joaquim Cesar Pizzutti dos Santos

Programa de Pós-Graduação em Engenharia Civil | Universidade Federal de Santa Maria | E-mail: joaquimpizzutti@hotmail.com

Jorge Luiz Pizzutti dos Santos

Programa de Pós-Graduação em Engenharia Civil | Universidade Federal de Santa Maria | E-mail: jorgepizzutti@gmail.com
\end{abstract}

\title{
Ambiente Construído
}

Revista da Associação Nacional de Tecnologia do Ambiente Construído

Av. Osvaldo Aranha, $99-3^{\circ}$ andar, Centro

Porto Alegre - RS - Brasil

CEP $90035-190$

Telefone: +55 (51) 3308-4084

www.seer.ufrgs.br/ambienteconstruido www.scielo.br/ac

E-mail: ambienteconstruido@ufrgs.br 